Illinois State University

ISU ReD: Research and eData

Theses and Dissertations

$3-24-2020$

\title{
Exploring Emotions at Work: The Effects of Trait Affect and Display Rules on Co-rumination
}

Miranda Maher

Illinois State University, mcmaher1214@gmail.com

Follow this and additional works at: https://ir.library.illinoisstate.edu/etd

Part of the Psychology Commons

\section{Recommended Citation}

Maher, Miranda, "Exploring Emotions at Work: The Effects of Trait Affect and Display Rules on Corumination" (2020). Theses and Dissertations. 1224.

https://ir.library.illinoisstate.edu/etd/1224

This Thesis is brought to you for free and open access by ISU ReD: Research and eData. It has been accepted for inclusion in Theses and Dissertations by an authorized administrator of ISU ReD: Research and eData. For more information, please contact ISUReD@ilstu.edu. 


\section{EXPLORING EMOTIONS AT WORK: THE EFFECTS OF TRAIT AFFECT AND DISPLAY \\ RULES ON CO-RUMINATION}

\section{MIRANDA MAHER}

\section{Pages}

This study aimed to examine the relation between trait affect and co-rumination, and the mediating role of display rules on the affect-co-rumination association. The moderating role of affectivity on the relation between display rules and co-rumination was also examined. Affectivity was examined as a moderator of its own indirect effect to test for moderatedmediation. For data collection, MTurk was used to generate a sample of 338 US employees. Participants received affectivity, display rules, and co-rumination measures at one time point. Results showed that affectivity is related to one's display rule perceptions, with negative affectivity predicting negative display rules and positive affectivity predicting positive display rules. Positive display rules, but not negative display rules, predicted increased co-rumination. Both positive and negative affectivity predicted increased co-rumination. Display rules were not found to mediate the affectivity-co-rumination association. Lastly, affectivity was not found to moderate the display rules-co-rumination association, thus ruling out the possibility of moderated-mediation. Contrary to prediction, this study demonstrates that co-rumination may occur regardless of one's affectivity. Further, it suggests that work environments with positive display rules may be particularly susceptible to co-rumination. This study articulates the importance of creating work environments that support the emotional needs of employees. KEYWORDS: affect; display rules; co-rumination 
EXPLORING EMOTIONS AT WORK: THE EFFECTS OF TRAIT AFFECT AND DISPLAY

RULES ON CO-RUMINATION

MIRANDA MAHER

A Thesis Submitted in Partial

Fulfillment of the Requirements

for the Degree of

MASTER OF SCIENCE

Department of Psychology

ILLINOIS STATE UNIVERSITY

2020 
(C) 2020 Miranda Maher 


\section{EXPLORING EMOTIONS AT WORK: THE EFFECTS OF TRAIT AFFECT AND DISPLAY RULES ON CO-RUMINATION}

MIRANDA MAHER

COMMITTEE MEMBERS:

Jeffrey H. Kahn, Chair

Kimberly T. Schneider 


\section{ACKNOWLEDGMENTS}

First, I'd like to express my gratitude to my thesis committee. My thesis chair, Dr. Kahn, has been extremely supportive and helpful through every step of the process. From brainstorming research ideas during my first year in the program, to offering feedback on my final draft, I have greatly appreciated his time and mentorship. His advice and feedback will definitely stay with me beyond my graduate school experience. Thanks also to Dr. Schneider for providing valuable insight into emotional labor research. Her research and expertise have furthered my passion for studying stress and emotions in the workplace. I'd also like to offer special thanks to Dr. Braswell for dedicating his time and feedback as a reader.

I'd also like to thank the rest of the faculty in the IOS and Quantitative sequences. My thesis is a product of the coursework, feedback, and mentorship I've received from all the faculty members in our program. I am extremely grateful to soon be a proud alumna of our program.

M. M. 


\section{CONTENTS}

Page

ACKNOWLEDGMENTS

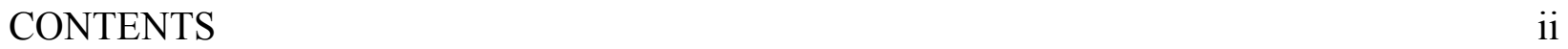

TABLES

FIGURES

CHAPTER I: GENERAL LITERATURE REVIEW

$\begin{array}{ll}\text { Display Rules } & 1\end{array}$

Positive and Negative Display Rules 2

Affect and Display Rules $\quad 4$

$\begin{array}{ll}\text { Social Support } & 6\end{array}$

$\begin{array}{ll}\text { Co-Rumination } & 6\end{array}$

Display Rules and Co-rumination $\quad 8$

$\begin{array}{ll}\text { Affect and Co-rumination } & 10\end{array}$

$\begin{array}{ll}\text { Conditional Process Modeling } & 14\end{array}$

Display Rules as a Mediator 16

$\begin{array}{ll}\text { Trait Affect as a Moderator } & 18\end{array}$

$\begin{array}{ll}\text { Moderated-Mediation } & 20\end{array}$

CHAPTER II: RESEARCH DESIGN

$\begin{array}{ll}\text { Method } & 21\end{array}$

$\begin{array}{ll}\text { Participants and Procedure } & 21\end{array}$

$\begin{array}{ll}\text { MTurk } & 23\end{array}$

$\begin{array}{ll}\text { Measures } & 24\end{array}$ 
$\begin{array}{ll}\text { CHAPTER III: RESULTS } & 26\end{array}$

$\begin{array}{ll}\text { Overview of Analyses } & 26\end{array}$

Descriptive Information and Hypothesis Testing 26

$\begin{array}{ll}\text { Hypothesis Testing } & 28\end{array}$

$\begin{array}{ll}\text { Hypothesis } 1 & 28\end{array}$

$\begin{array}{ll}\text { Hypothesis } 2 & 29\end{array}$

$\begin{array}{ll}\text { Hypothesis } 3 & 29\end{array}$

$\begin{array}{ll}\text { Hypothesis } 4 & 29\end{array}$

$\begin{array}{ll}\text { Hypothesis } 5 & 30\end{array}$

$\begin{array}{ll}\text { Hypothesis } 6 & 32\end{array}$

CHAPTER IV: DISCUSSION

$\begin{array}{ll}\text { Summary of Findings } & 35\end{array}$

$\begin{array}{ll}\text { General Discussion } & 36\end{array}$

$\begin{array}{ll}\text { Limitations } & 41\end{array}$

Theoretical and Practical Implications 43

REFERENCES $\quad 45$ 


\section{TABLES}

Table

Page

1. Correlations, means and standard deviations for the variables of interest

2. Co-rumination levels by occupation type

3. Moderated-mediation analysis with negative affectivity and negative display rules

4. Moderated-mediation analysis with positive affectivity and positive display rules 


\section{FIGURES}

Figure

Page

1. Hypothesized conditional process model for positive trait affect, positive display rule perceptions, and co-rumination

2. Hypothesized conditional process model for negative trait affect, negative display rule perceptions, and co-rumination

3. Participant flow diagram

4. Two-way interaction between negative display rules and negative affectivity

5. Two-way interaction between positive display rules and positive affectivity 


\section{CHAPTER I: GENERAL LITERATURE REVIEW}

\section{Display Rules}

First introduced by Ekman and Friesen (1969), display rules provide a framework for appropriate emotional expressions at work. Specifically, they prescribe which emotions should or should not be displayed in the workplace. By setting these rules, organizations aim to promote the completion of workplace goals without the interference of emotions (Ashforth \& Humphrey, 1993). Employees tend to perceive display rules as lower-level work goals (Ashkanasy et al., 2016). Previous research suggests display rules may lead to enhanced job performance and organizational functioning (Diefendorff \& Gosserand, 2003). They have also been found to define behaviors necessary for organizational success (Diefendorff \& Richard, 2003). In this way, display rules have the potential to facilitate organizational development by standardizing emotional expressions at work.

Display rules tend to differ in their degree of salience across organizations. Display rules can be communicated to employees explicitly and implicitly (Becker, 2013). The explicit communication of display rules can occur through organizational procedures like training, selection, and reward systems (Leidner, 1999; Rafaeli \& Sutton, 1987). Implicit communication can occur through cultural cues and social norms at work (Becker, 2013). These different communication styles lead display rules to differ in their degree of salience across organizations. In a study examining the perception of display rules across organizations, employees and supervisors mainly defined display rules as formal, in-role job demands (Diefendorff et al., 2006). Thus, while display rules may vary across organizations, they tend to constitute a key feature of most work environments. 


\section{Positive and Negative Display Rules}

Given that display rules differ in their degree of salience across organizations, this construct is typically measured through individual perceptions. Display rule perceptions can be defined as "individual perceptions of how pressures exist for employees to show organizationally preferred emotions, regardless of their true feelings" (Kammeyer-Mueller et al., 2013, p. 51). Under this construct, display rules are characterized by two dimensions: positive and negative display rule perceptions. Positive display rules are perceived demands to express positive emotions whereas negative display rules are perceived demands to suppress negative emotions (Diefendorff \& Richard, 2003; Schaubroeck \& Jones, 2000).

In an organizational context, examples of positive and negative display rules can be observed. Positive display rules are typical of environments requiring "service with a smile" when interacting with customers. Under positive display rules, service employees are required to display positive emotion regardless of felt emotion (Grandey \& Sayre, 2019). In environments with negative display rules, employees are required to hide negative emotions. Organizations with negative display rules may require employees to hide feelings like anger, boredom, or irritation without providing rules related to positive emotions (Becker, 1983). In both display rule types, the effortful process to manage emotions is referred to as emotional labor (Hochschild, 1983). This process is characterized by the comparison of one's emotional displays against display rules to ensure the displays are appropriate (Diefendorff \& Gosserand, 2003). By doing so, employees execute emotion work to ensure their public displays align with organizational expectations.

Drawing on past research by Goldberg and researchers (2007), Becker (2013) defined four separate aspects of positive and negative display rules. These four aspects include 
integrative display rules, negative display rules, positive display rules, and display autonomy.

Each aspect is characterized by whether positive and negative display rules are present or absent. First, integrative display rules involve the presence of both positive and negative display rules. Second, negative display rules involve the presence of negative, but not positive, display rules. Third, positive display rules involve the presence of positive, but not negative, display rules. Fourth, display autonomy indicates the absence of both positive and negative display rules, thus permitting employees to exhibit volition in their emotional displays. Thus, it is assumed that positive and negative display rules are distinct factors. Past research has confirmed this notion by indicating that positive and negative display rules are separate factors with high reliabilities (Diefendorff et al., 2005; Diefendorff \& Richard, 2003; Schaubroeck \& Jones, 2000).

Research suggests that positive and negative display rules lead to different outcomes. Although negative display rules are less common in both research and practice (Trougakos et al., 2011), they have been consistently linked with negative outcomes. Negative display rules have been related to reduced job satisfaction (Diefendorff \& Richard, 2003), increased emotional exhaustion (Chau, 2007), decreased feelings of personal accomplishment (Brotheridge \& Grandey, 2002), and feelings of depersonalization (Brotheridge \& Grandey, 2002). While positive display rules have also been linked with some negative outcomes including increased emotional dissonance and cynicism (Montgomery et al., 2006), most research has linked positive display rules with better outcomes. Specifically, positive display rules have been associated with increased job satisfaction (Diefendorff \& Richard, 2003), professional efficacy (Kim, 2008), and increased feelings of personal accomplishment (Brotheridge \& Grandey, 2002). These findings suggest that the outward expression of positive emotion leads to some internal benefits. Further, it is evident that positive and negative display rules differentially impact employees at work. 
Different outcomes for positive and negative display rules can also be examined concurrently. In an experimental design, participants were instructed to either suppress emotions or express positive emotions (Trougakos et al., 2011). Compared to those who expressed positive emotions, participants who suppressed negative emotions exhibited decreased task persistence and increased avoidant behavior. In a similar experiment conducted by Hopp and colleagues (2012), participants were instructed to either express positive emotions or suppress negative emotions in a service interaction with an unhappy customer. The demands to suppress negative emotions were found to reduce well-being while demands to express positive emotion were found to enhance service quality. Specifically, the researchers found that service quality only increased when demands to express positive emotion did not include any instructions to suppress negative emotions. Thus, the researchers recommend that service organizations implement demands to express positive emotions while avoiding demands to suppress negative emotions. In terms of display rules, this suggests that positive display rules may enhance service quality without negatively impacting well-being. This further highlights the potential consequences of negative display rules in organizations.

\section{Affect and Display Rules}

Past research suggests that display rule perceptions tend to vary across organizations. This variance can be attributed to numerous factors including organizational norms (Ashforth \& Humphrey, 1993), work demands (Sutton \& Rafaeli, 1988), and individual differences (Kammeyer-Mueller et al., 2013). Specific to individual differences, emotional predispositions have been found to influence display rule perceptions (Kammeyer-Mueller et al., 2013). One type of emotional predisposition is trait affect. Research suggests that trait negative affect is associated with perceived negative display rules whereas positive affect is associated with 
perceived positive display rules (Brotheridge \& Grandey, 2002; Rouxel et al., 2016). In a sample of geriatric care workers, negative affectivity was found to positively predict perceived negative display rules (Rouxel et al., 2016). Further, a meta-analysis explored the relationships between trait affect with both positive and negative display rules (Kammeyer-Mueller et al., 2013). Across 12 studies, positive affectivity was found to be related to positive display rule perceptions $(\rho=.26)$. Across 7 studies, negative affectivity was found to be related to negative display rule perceptions $(\rho=.13)$. This indicates that affect may differentially influence display rule perceptions.

The relation between affect and display rule perceptions can be better examined using the trait-congruency processing framework. This theory asserts that people are likely to attend to stimuli congruent with their individual traits, including trait affectivity (Rusting, 1998). Further, individuals are likely to interpret their environment based on affect (Rusting, 1998). Thus, it is reasonable to expect that employees high in negative affectivity will perceive workplace stimuli, namely display rules, differently from employees high in positive affect. Further, those high in negative affectivity may need to work harder to suppress the negative emotions they are prone to displaying (Allen et al., 2010; Diefendorff \& Richard, 2003). Using this framework, I predicted that individuals with high levels of negative affect would be more likely to interpret their organization's display rules negatively. I also predicted that individuals with high positive affect would be inclined to interpret display rules positively.

H1a: High negative affectivity will lead to increased levels of perceived negative display rules.

H1b: High positive affectivity will lead to increased levels of perceived positive display rules. 


\section{Social Support}

When employees are limited in their ability to display authentic emotions at work, social support from co-workers offers a meaningful outlet. Social support is characterized by both verbal and nonverbal communication that is either helpful or intended to be helpful (Sias, 2009). In the workplace, support can come in numerous forms including emotional, informational, and instrumental support (Sias, 2009). Social support has been found to reduce the negative effects of stress in the workplace, including role stress (Matthews et al., 2010), and to increase subjective well-being (Chou, 2015). Further, social support has been found to mediate the negative relation between emotional demands and job satisfaction, thus providing a buffer against the consequences of emotional work (Roxana, 2013).

Past research has developed various theoretical perspectives on social support. The primary theory identified in the literature is the stress and coping perspective (Cohen et al., 2000). This theory asserts that social support reduces the effects of stress on health. This relationship is hypothesized to be moderated by one's coping ability, which is thought to be enhanced by the support received (Cohen et al., 2000). This framework articulates the process by which social support acts as a stress buffer. In an organizational context, it demonstrates why social support may be a useful coping mechanism for employees.

\section{Co-Rumination}

About 3 in 4 Americans report having someone they can count on to provide social support, an 8\% increase from 3 years prior (American Psychological Association, 2009). As social support continues to grow in importance, it is necessary to examine its effectiveness. Recent research has identified the content of social support as a main factor in determining whether the support is helpful (Boren, 2014). Co-rumination, involving the excessive discussion 
of personal problems between two people, provides an example of negative social support content. In this form of dyadic communication, support is provided by "frequently discussing problems, discussing the same problem repeatedly, mutual encouragement of discussing problems, speculating about problems, and focusing on negative feelings" (Rose, 2002, p. 1830).

With its roots in developmental psychology, co-rumination has primarily been observed in school settings. Rose's (2002) research explores the nuances of co-rumination, suggesting that it can lead to both adaptive and maladaptive outcomes. For example, first observed in girl and boy friendships, co-rumination was found to be positively correlated with friendship quality and closeness (Rose, 2002). This indicates that the self-disclosure involved in rumination has the potential to bring people together. However, co-rumination has also been linked with depression contagion in adolescents (Schwartz-Mette \& Smith, 2018), depression and anxiety in adolescent friendships (Rose, 2002), and internalizing symptoms (Rose, 2002; Rose et al., 2007). Thus, corumination may lead people to perceive emotional closeness while simultaneously negatively impacting their well-being.

Recent research has extended co-rumination beyond adolescence. Given the collaborative nature of the work environment in which employees discuss organizational problems, it is reasonable to expect co-rumination at work. Although it has yet to be studied extensively in organizations, preliminary findings shed light on this phenomenon. In organizations, corumination has been associated with work-to-family conflict (Haggard et al., 2011). Further, corumination has been found to reduce the negative relation between social support with both burnout and perceived employee stress (Boren, 2014). Similarly, co-rumination was found to reduce the negative relation between social support and emotional exhaustion among graduate 
students (Boren, 2013). Together, these findings suggest that co-rumination also leads to negative outcomes in the work environment.

\section{Display Rules and Co-rumination}

Past research suggests that both negative and positive display rules lead to emotion suppression (Becker, 2013). Emotion suppression is defined as the "conscious inhibition of one's own emotional expressive behavior while emotionally aroused" (Gross \& Levenson, 1993, p. 970). The study of suppression initially focused on thought suppression, characterized by effortful attempts to avoid thinking about a target (Yam, 2018). First examined through research by Wegner (1989), participants in an experimental design were instructed to avoid thoughts of a white bear. Participants were unable to avoid thoughts of the white bear despite instruction, thus providing evidence for the challenges of thought suppression. This paradoxical effect has been attributed to the mental and behavioral rebounds that occur during attempts to suppress (Abramowitz et al., 2001). Specifically, Wegner (1994) used ironic process theory to explain the mental processes that are activated during thought suppression. The first mental process, the conscious operating process, attempts to suppress by searching for different thoughts (e.g., distractions). The second mental process, the nonconscious monitoring process, checks for any errors in suppression. Thus, ironic process theory examines how individual attempts to suppress may be counterintuitive.

In addition to thought suppression, ironic process theory has also been examined in terms of emotion suppression. For instance, participants high in negative affect experienced ironic effects when instructed to suppress negative emotion while writing about a distressing personal memory (Dalgleish et al., 2009). This study provides evidence that emotion suppression may lead to a paradoxical return of undesired emotions. Further, instructions to suppress emotions 
have been found to lead to impaired recall and recognition memory (Richards \& Gross, 1999), increased cardiovascular arousal (Ben-Naim et al., 2013), and decreased relationship formation during social interactions (Butler et al., 2003). Emotion suppression has also been associated with an increase in depressive symptoms (Brenning et al., 2015). Thus, emotion suppression required by display rules may interfere with typical cognitive, physiological, and social functioning.

The findings on emotion suppression demonstrate why both positive and negative display rules lead to negative outcomes at work. However, compared to negative display rules, the suppression in positive display rules might not be as detrimental. Using approach-avoidance theory, these differences can be examined. When exposed to different stimuli, approachavoidance theory asserts that people respond by moving toward (approach) or moving away from (avoidance) the given stimuli (Ferris, 2016). Past research suggests that negative goals tend to lead to avoidant responses while positive goals lead to approach responses (McNaughton et al., 2016). This framework has been applied to emotions, indicating that the expression of positive emotions signal approach goals (Lyubomirsky et al., 2005). Thus, positive display rules may activate approach behaviors, thus leading employees to approach positive emotions. Negative display rules may activate avoidance behaviors, thus leading employees to actively suppress emotions. In this way, approach-avoidance theory highlights the different behaviors activated under positive and negative display rules. Particularly, it suggests that negative display rules may lead employees to more strongly suppress emotions.

Further, research has highlighted the benefits of expressing positive emotions. In organizations, expressing positive emotions has been positively correlated with customer satisfaction (Pugh, 2001), task completion (Ashforth \& Humphrey, 1993), goal attainment 
(Wong et al., 2013), and various financial outcomes (e.g., sales, tips) (Rafeli \& Sutton, 1987).

Expressing positive emotions can also involve emotional contagion, thus leading to positive affect across entire work groups (Sy et al, 2005; Wong et al., 2013). Due to the benefits of expressing positive emotions, employees in environments with positive display rules may have less to complain about at work.

For those exposed to negative display rules, emotion suppression may lead to negative outcomes, including increased psychological distress (Cohen, 2013). Thus, those exposed to negative display rules may desire to express suppressed emotions. Specifically, employees may look to social support as an outlet to deal with suppressed emotions. Past research suggests that talking to others about problems is a common coping mechanism (Narayanan et al., 1999). As individuals seek to cope with suppressed emotions, they may be particularly likely to talk to others about their problems. Given that co-rumination is a form of emotion-focused social support (Starr, 2015), I predicted that negative display rule perceptions would lead to increased co-rumination. As environments with positive display rules more strongly emphasize the expression of positive emotions, I expected that positive display rule perceptions would lead to decreased co-rumination.

H2a: Negative display rule perceptions will be positively related to co-rumination.

H2b: Positive display rule perceptions will be negatively related to co-rumination.

\section{Affect and Co-rumination}

As co-rumination is characterized by dwelling on negative affect (Rose, 2002; SchwartzMette \& Smith, 2018), past research has explored its link with state affect. Specifically, participants exposed to a co-ruminative interviewing style were found to demonstrate increased state negative affect (Zelic, 2017). Similarly, content analyses of Facebook messages revealed 
that co-rumination is characterized by state negative affect focus (Swearingen et al., 2016). Further, co-rumination in Facebook messaging was found to predict state negative affect in later conversations (Swearingen et al., 2016). Due to conversations focused on negative content, corumination is likely to lead to increased state negative affect.

While research has focused on co-rumination and state affect, trait affect has yet to be explored. This study considers the relation between co-rumination and both trait positive and trait negative affectivity. First, negative affect will be considered. In a study conducted by Kahn and colleagues (2006), the relation between affectivity and social support content among teachers was explored. Negative affectivity was found to be positively associated with negative support, characterized by a focus on the negative aspects of work. Given that co-rumination is one type of negatively focused social support, it may similarly be related to negative affectivity.

Affect expression suggests a possible linkage between negative affect and co-rumination. Specifically, affect expression has been identified as an individual trait that tends to be relatively stable across the lifespan (Kennedy-Moore \& Watson, 2001). In this way, individuals vary in the degree to which they express affect. Specifically, past research suggests that individuals high in trait negative affect engage in high levels of negative affect expression (Carver \& Connor-Smith, 2010). Given that co-rumination involves the expression of negative affect, those high in trait negative affect may be more likely to co-ruminate compared to those with low trait negative affect. If confirmed, this would indicate that co-rumination and negative-affect expression may be related.

Individual differences attributable to negative affect can also be examined regarding corumination. First, past research indicates that negative affectivity leads to challenges in cognitive restructuring and positive thinking (Carver \& Connor-Smith, 2010). Compared to individuals 
with low negative affect, individuals high in negative affect may be prone to talking about their negative thoughts with others. Based on this individual difference, those with high trait negative affect may be more susceptible to co-ruminating than those with low negative affect. Second, trait negative affect has been strongly correlated with neuroticism (Joseph et al., 2015). Further, neuroticism has been found to lead to increased co-rumination (Guarneri-White, 2017). Given the relation between trait negative affect and neuroticism, there is reason to expect trait negative affect lead to co-rumination.

The rumination literature offers further support for the relation between trait negative affect and co-rumination. Rumination is defined as the repetitive thought process surrounding one's problems or depressive symptoms. The two constructs can be differentiated as corumination is a verbal form of rumination (Rose, 2002). Past research suggests that corumination and rumination are strongly and positively correlated (Felton, 2019). In terms of rumination and trait affect, Costa and colleagues (2018) found that trait negative affect led to rumination among both depressed outpatients and normative individuals. In a sample of undergraduates, trait negative affect was also found to predict rumination (Valena \& Szentagotái-Tatar, 2015). When asked to report on a stressful life event, trait negative affect led to fear-induced rumination among college students (Kamijo \& Yukawa, 2018). Together, these findings suggest that individuals high in trait negative affect are susceptible to repetitive and distressful thoughts. There is reason to expect these thoughts to transfer into everyday conversation with peers. Thus, I predicted that trait negative affect would be positively related to co-rumination.

H3a: Negative affectivity will be positively related to co-rumination. 
Next, positive affect will be considered. Past research has also examined the relation between personality traits and the content of social support in organizations (Zellars \& Perrewé, 2001). Using a sample of nurses, participants indicated the extent to which the social support they received at work was positively or negatively focused. Positive conversations were characterized by a focus on the rewarding aspects of nursing while negative conversations emphasized workplace issues (e.g., problems with patients). Extraversion and agreeableness were found to predict engagement in conversations with a positive focus. Given that trait positive affect has been positively associated with both extraversion and agreeableness (Işı1k \& Üzbe, 2015), there is reason to expect individuals high in positive affect to similarly engage in conversations with a positive focus.

Response styles to positive affect have been explored among individuals with trait positive affectivity. One response style to positive affect includes positive rumination. While rumination focuses solely on negative events or affective experiences (Harding \& Mezulis, 2017), positive rumination offers a difference approach. Positive rumination responds to positive affective experiences by increasing positive emotions focused on the self or one's emotional state (Hamilton et al., 2017). Research suggests that positive rumination is a protective factor against depression (Feldman, Joormann, \& Johnson, 2008). In one study, trait positive affect was found to be positively associated with positive rumination (Hamilton et al., 2017). Further, those high in trait positive affect were less likely to engage in dampening, a positive rumination strategy characterized by downgrading one's response to positive affect (Hamilton et al., 2017). Instead, individuals high in positive affect have been found to engage in enhancing, a positive rumination strategy that involves increasing one's experience of positive affect (Nelis et al., 
2018). This suggests that individuals high in positive affect are more prone to amplifying their positive affective experiences.

In an organizational context, individuals high in positive affect are more likely to be satisfied with their jobs (Watson \& Slack, 1993; Connolly \& Viswesvaran, 2000). In part, this can again be attributed to trait congruency theory. Based on their tendency to perceive the workplace positively, individuals with high positive affect may also have fewer complaints about their jobs. This further illustrates why individuals high in positive affect may not exhibit the need to co-ruminate. Drawing on past research, I predicted that high positive affectivity would be negatively related to co-rumination.

H3b: Positive affectivity will be negatively related to co-rumination.

\section{Conditional Process Modeling}

Now that the bivariate relations between affect, display rules, and co-rumination have been proposed, the role of third variables will also be considered. In psychological research, various models involving third variables are statistically examined beyond bivariate associations. Two of these models include moderation and mediation analyses. First, moderation provides an example of a linear interaction analysis. Moderation examines the role of a variable (i.e., moderator) that changes the direction and/or strength of a relation between a focal predictor and a dependent variable (Hayes, 2018). For example, a moderating variable may significantly strengthen a proposed bivariate relationship, thus demonstrating that other variables influence the given association. To test for moderation, an interaction term, characterized by the product of the focal predictor and the moderator, is examined for statistical significance (Hayes, 2017). In organizational research, moderators improve one's ability to estimate the stimuli that interact 
with the environment, thus producing differential outcomes. In this way, moderation leads to an improved understanding of the nuances behind factors influencing behavior at work.

Second, mediation examines a third variable (i.e., mediator) through which a focal predictor influences a criterion variable. This mediating variable is often referred to as the "mechanism" behind a given relation, providing an explanation as to why a criterion changes in response to a predictor (Hayes, 2018). Moderation and mediation analyses can be contrasted from one another as moderators always operate as independent variables while mediators can operate as effects or causes (Baron \& Kenny, 1986). Further, moderation demonstrates when given effects take place whereas mediation explains the why or how behind such effects (Baron \& Kenny, 1986). Thus, mediation is helpful in explaining the mechanism behind given organizational phenomena.

Although moderation and mediation offer different approaches to third variable analyses, they can be examined simultaneously. Specifically, conditional process modeling is one method that statistically integrates moderation and mediation analyses (Hayes, 2018). Conditional process modeling examines the conditional nature of mediation, indicating contingency upon certain levels of a given moderator (Hayes, 2018). As defined by Hayes (2018), one form of this model involves a predictor that moderates its own indirect effect on a criterion through a mediating variable. Given this study's proposed bivariate relations, this model offers a reasonable fit for the study. The hypothesized models are demonstrated in Figure 1 and Figure 2. Thus, the following hypotheses consider moderation and mediation analyses in the context of the given conditional process model. First, the mediating role of display rules on the trait affect-corumination association is explored. Second, the moderating role of trait affect on the relation between display rules and co-rumination is examined. Using conditional process modeling, the 
contingent nature of the proposed linkages between affect, display rules, and co-rumination can be explored.

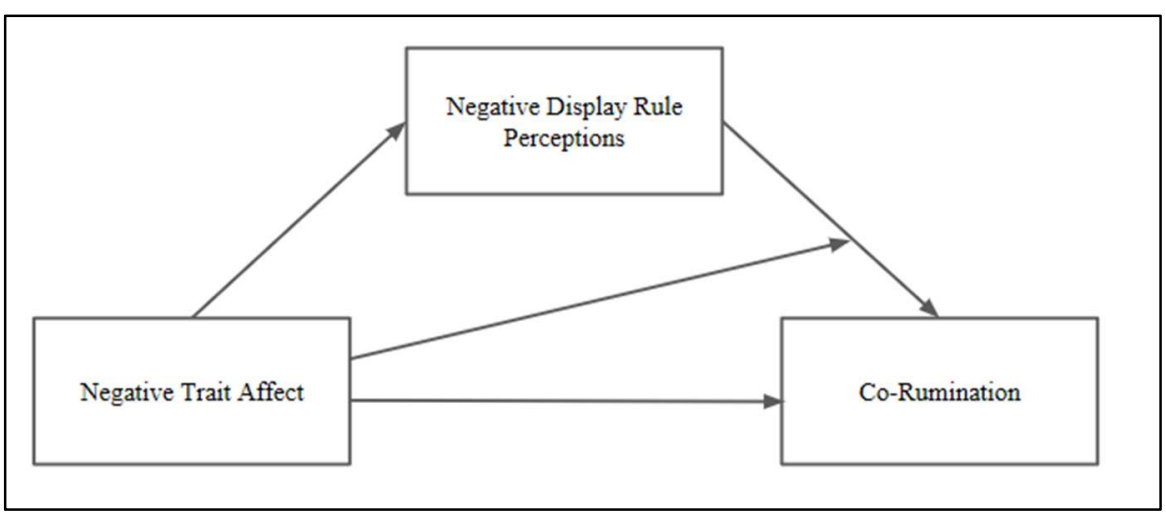

Figure 1. The hypothesized relations between negative trait affect, negative display rule perceptions, and co-rumination.

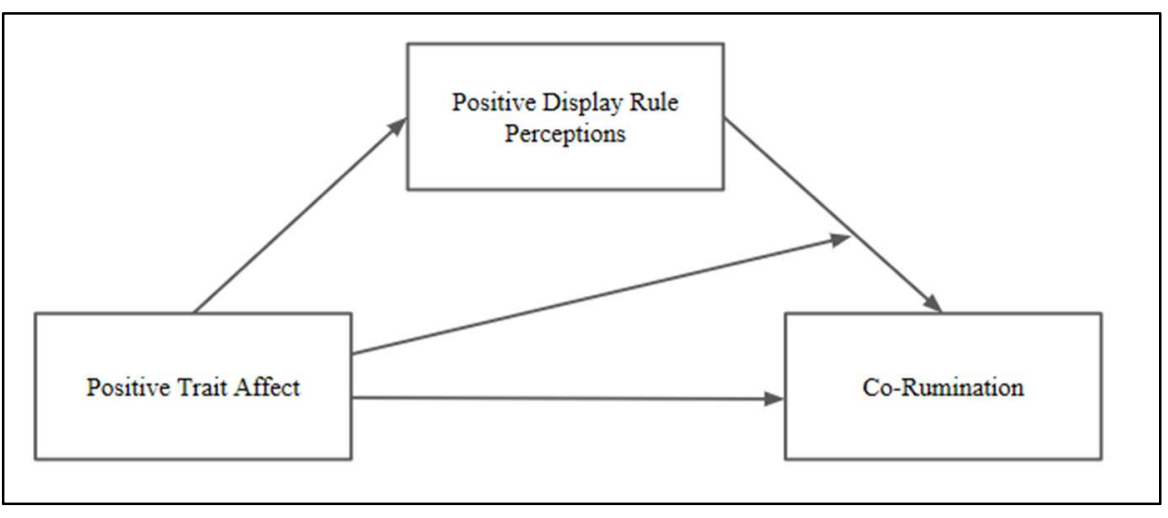

Figure 2. The hypothesized relations between positive trait affect, positive display rule perceptions, and co-rumination.

\section{Display Rules as a Mediator}

Drawing on the proposed bivariate relations, the role of negative display rule perceptions can be examined as a mediator. First, it was predicted that negative affect would lead to negative display rule perceptions. Second, it was predicted that negative display rule perceptions would lead to increased co-rumination. Third, it was predicted that negative affect would lead to increased co-rumination. Together, these hypotheses suggest that negative display rules may 
mediate the proposed positive relation between negative affect and co-rumination. Specifically, negative display rules were expected to explain why individuals high in negative affect are more likely to co-ruminate. For example, consider an employee with high negative affect at work. Given their proneness to experiencing negative emotions, they would likely perceive their organization's display rules as highly restrictive. By perceiving the presence of negative display rules, the employee would likely feel pressured to hide negative emotions at work. Thus, the employee would feel compelled to co-ruminate with co-workers to express their suppressed emotions. Under this model, negative display rules can be characterized as the mechanism by which negative affect increases co-rumination.

Next, positive affect will be considered. First, it was predicted that positive affect will lead to positive display rule perceptions. Second, it was predicted that positive display rule perceptions will lead to decreased co-rumination. Third, it was predicted that positive affect will lead to decreased co-rumination. Together, these hypotheses suggest that positive display rules may mediate the negative relation between positive affect and co-rumination. Thus, positive display rules are expected to explain why individuals high in positive affect are less likely to coruminate. For example, consider an employee with high positive affect at work. Given their proneness to experiencing positive emotions, they would likely possess positive display rule perceptions. By perceiving the expectation to exhibit positive emotion, the employee would behave positively at work. Given the benefits of expressing positive emotions at work, the employee would not feel compelled to co-ruminate with co-workers. Under this model, positive display rules can be characterized as the mechanism by which positive affect decreases corumination. 
In support of this logic, it is important to consider the temporal ordering of the given variables. First, affect tends to be stable across the lifespan (Watson \& Walker, 1996), indicating that it would likely precede display rules and co-rumination. Second, display rules are a characteristic, or perceived characteristic, of one's work environment. Third, co-rumination tends to fluctuate in response to workplace stressors. Thus, it is reasonable to expect an individual trait (affect) to alter perceptions of the organizational environment (display rules), thus leading to differential behavioral outcomes at work (co-rumination). The temporal ordering of variables further supports the following hypotheses:

H4a: Negative display rule perceptions will mediate the positive relation between negative affectivity and co-rumination.

H4b: Positive display rule perceptions will mediate the negative relation between positive affectivity and co-rumination.

\section{Trait Affect as a Moderator}

Next, as suggested in the conditional processing model, the moderating influence of a predictor on its own indirect effect can be explored (Hayes, 2017). Specifically, trait affect is examined as a proposed moderator on the display rules-co-rumination association. First, the association between negative display rules and co-rumination is predicted to be stronger among those higher in negative affect. Individuals high in negative affect tend to exhibit negative emotions like disgust and worry (Fredrickson \& Branigan, 2005). However, negative display rules require employees to hide negative emotions. Thus, individuals high in negative affect likely have more negative emotions to suppress compared to individuals low in negative affect. As discussed previously, emotion suppression leads to a variety of negative outcomes. Given the heightened level of emotion suppression required for individuals high in negative affect under 
negative display rules, co-rumination would likely increase. Thus, for those high in negative affect, I predicted that there would be a positive relation between negative display rules and corumination. However, for those low in negative affect, I predicted that there would be a weaker relation between negative display rules and co-rumination.

H5a: Negative affectivity will moderate the positive relation between negative display rules and co-rumination such that the positive relation is stronger when the level of negative affectivity is higher.

Second, I predicted that the negative relation between positive display rules and corumination would depend on levels of positive affect. Research suggests that individuals high in trait positive affect tend to experience positive emotions including enthusiasm and happiness (Barsade \& Gibson, 2007). As mentioned previously, positive display rules require employees to express positive emotions at work. Compared to those low in positive affect, it is reasonable to expect those high in positive affect to more easily meet the demands of positive display rules. Given their natural propensity to experience positive emotions, individuals high in positive affect may also have fewer emotions to hide at work. Further, this group may be less likely to experience emotion suppression, indicating a decreased susceptibility to the negative outcomes of emotional suppression, such as co-rumination. For those high in positive affect, I predicted that there would be a negative relation between positive display rules and co-rumination. However, for those low in positive affect, I predicted that there would be a weaker relation between positive display rules and co-rumination. 
H5b: Positive affectivity will moderate the negative relation between positive display rules and co-rumination such that the relation is stronger when the level of positive affectivity is higher.

\section{Moderated-Mediation}

Together, the moderation and mediation hypotheses can be integrated to examine the extent to which mediation is contingent upon different levels of trait affect. First, I predicted that the extent to which negative display rule perceptions mediate the relation between negative affect and co-rumination would depend upon levels of negative affect. Second, I predicted that the extent to which positive display rule perceptions mediate the relation between positive affect and co-rumination would depend upon levels of positive affect.

H6a: The degree to which negative display rules mediate the relation between negative affectivity and co-rumination will depend upon levels of negative affectivity such that the mediation will be stronger under high negative affectivity than under low negative affectivity.

H6b: The degree to which positive display rules mediate the relation between positive affectivity and co-rumination will depend upon levels of positive affectivity such that the mediation will be stronger under high positive affectivity than under low positive affectivity. 


\section{CHAPTER II: RESEARCH DESIGN}

\section{Method}

\section{Participants and Procedure}

This study used Amazon Mechanical Turk (MTurk) to collect responses from a focal sample of 593 US employees. Participants were required to be employed outside of MTurk, to

work with other employees/co-workers and to work with other employees/co-workers at least 10 hours per week (Diefendorff et al., 2005). I dropped 106 participants from the analyses because they did not meet the inclusion criteria. An additional 15 participants were dropped for completing the survey in under 2 minutes. Next, 76 participants were excluded for reporting on co-ruminative experiences involving a friend outside of work, instead of a friend at work (i.e., co-worker). Lastly, 58 participants were dropped for failing both manipulation checks. This resulted in a final sample size of 338 participants (175 women, 163 men). Figure 3 demonstrates the process by which participants were included in the final sample.

Currently, there are no data-based approaches to determining a sample size with Model 74. Instead, I based the given sample size on previous studies that have employed this statistical model, involving the moderating effect of $X$ on its own indirect effect. These studies reported sample sizes ranging from 249 to 417 participants (D'Lima et al., 2016; Gerhart et al., 2014; MacNeil et al., 2009). Thus, our final sample size of 338 participants aligns with previous research on Model 74. 


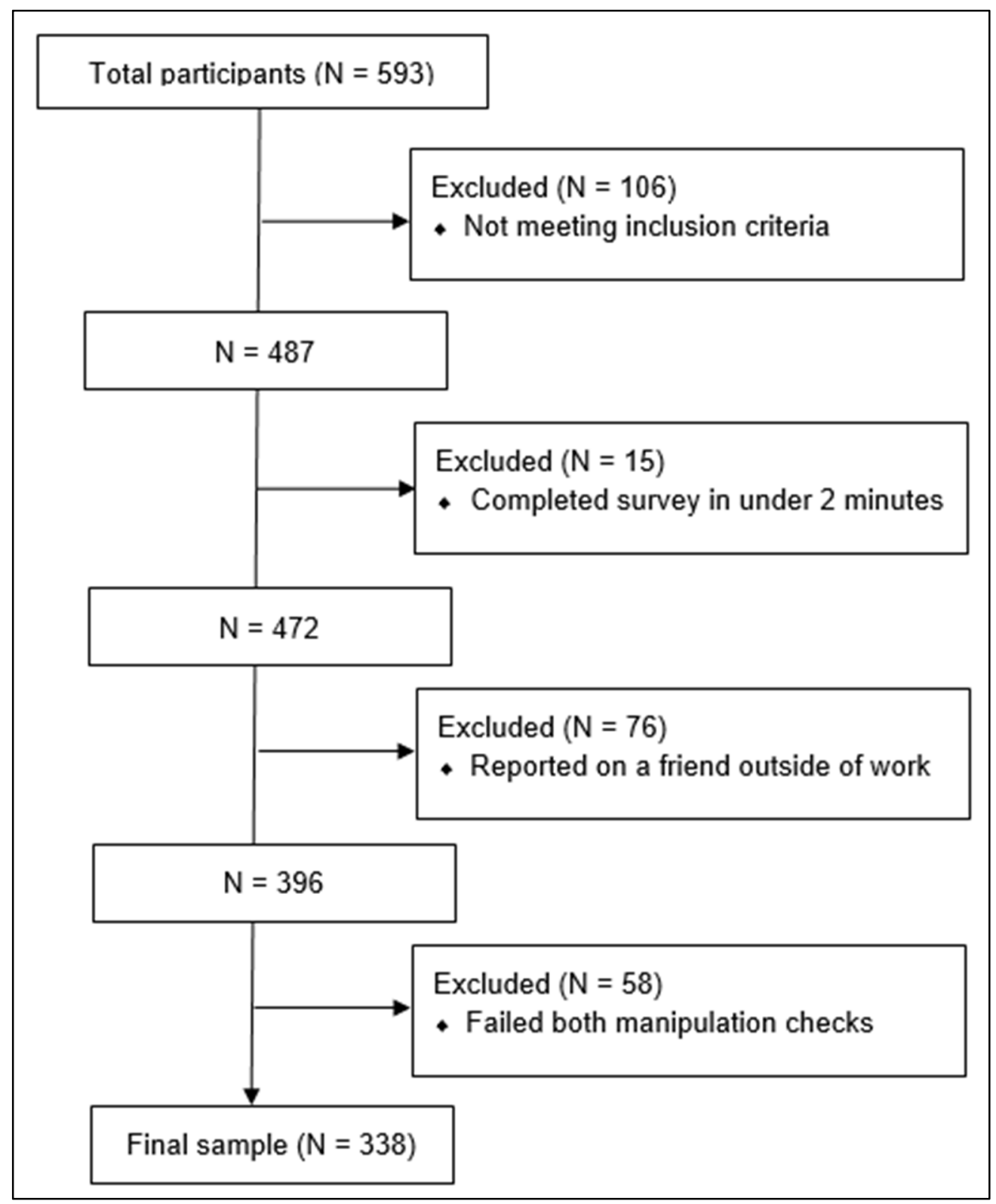

Figure 3. A flow diagram depicting the inclusion of study participants in the final sample.

The participants' ages ranged from 18 to 78 years $(M=35.67$ years, $S D=11.79$ years $)$.

Consistent with recent approaches in emotional labor research, employees from all industries were invited to participate (Brotheridge \& Grandey, 2002; Diefendorff et al., 2005). The participants were employed in a variety of industries, although the most common were Computer and Mathematical Occupations $(N=52)$, Sales and Related Occupations $(N=42)$, Educational 
Instruction and Library $(N=33)$, Business and Financial Operations $(N=38)$, Management Occupations $(\mathrm{N}=22)$, Healthcare Practitioners and Technical Occupations $(N=21)$, and Arts, Design, Entertainment, Sports, and Media Occupations $(N=20)$. The final sample was $67 \%$ White, 12\% Asian or Pacific Islander, 10\% Black or African American, 9\% Hispanic or Latinx, $1 \%$ Native American or American Indian, and 1\% other. All participants were surveyed at one time point. After deciding to participate, the display rule perceptions, co-rumination, and affect measures were administered. Participants were compensated $\$ .20$ for participating.

\section{MTurk}

Launched in 2005, MTurk has grown in popularity as a data collection tool among social scientists (Behrend et al. 2011), and specifically among industrial-organizational psychologists. Among the top 20 I-O psychology journals, studies using MTurk samples increased from 7 publications in 2012 to 44 publications in 2017 (Cheung et al., 2017). This increase in MTurk usage has also led to concerns over methodological issues. Past research has identified the primary methodological concerns with MTurk: subject inattentiveness, selection biases, demand characteristics, repeated participation, range restriction, consistency of study design implementation, extraneous factors, sample representativeness/appropriateness and method bias (Cheung et al., 2017).

Specifically, this study addressed concerns related to subject inattentiveness and sample representativeness/appropriateness. To address subject inattentiveness, two manipulation checks were included in the survey to be completed by participants. Both items required participants to identify the missing figure within a series of shapes in a video. As mentioned previously, only participants who responded to both manipulation checks correctly were included in the final sample. A benefit of MTurk is that it tends to provide quite heterogeneous samples, thus leading 
to increased external validity. However, this can also lead to reduced systematic covariation between variables. Thus, it is recommended that researchers restrict samples to the desired characteristics using qualification tests (Huang et al., 2015). Thus, rather than asking participants to indicate whether they worked and lived in the US, we used a qualification test embedded within the MTurk platform to recruit only US participants. By doing so, we aimed to increase the representativeness of our sample. Together, these recommendations were used in this study to address methodological concerns involving MTurk.

\section{Measures}

Perceived emotional display rules. Perceived display rules were measured using the perceived display rule demands measure developed by Diefendorff and colleagues (2005). This 7-item scale includes 4 items measuring positive display rules and 3 items measuring negative display rules. For positive display rules, a sample item includes: "My organization expects me to try to act excited and enthusiastic at work." For negative display rules, a sample item includes: "This organization expects me to try to pretend that I am not upset or distressed." All items that referred directly to interactions with customers were adapted to reference "others (e.g., customers, clients, co-workers)". Participants responded to items on a 5-point Likert scale ranging from 1 (strongly disagree) to 5 (strongly agree). Past research indicates alphas of .73 and .75 for positive and negative display rules, respectively (Diefendorff et al., 2005). In this sample, the positive display rule scale revealed an alpha of .69 and the negative display rule scale revealed an alpha of .86 .

Co-rumination. Co-rumination was measured using a 9-item adapted version of Rose's (2002) original 27-item co-rumination scale (Haggard et al., 2011). In this scale, one item measured each of the 9 co-rumination content areas including: frequently discussing problems, 
discussing problems instead of engaging in other activities, encouragement by the focal individual discussing problems, encouragement by the co-worker of the focal individual discussing problems, discussing the same problem repeatedly, speculation about problem causes, speculation about problem consequences, speculation about parts of the problem that are not understood, and focusing on negative feelings (Rose, 2002). Next, a prompt instructed participants to respond to the items while thinking of a person at work with whom they discuss work issues. Participants indicated their response to each of the nine items on a 5-point Likert scale ranging from 1 (not at all true) to 5 (really true). Haggard and researchers (2011) reported an alpha of .91 for the scale. In this study, the co-rumination scale also revealed an alpha estimate of .91 .

Trait positive and negative affectivity. Trait negative and positive affect were measured using the Positive and Negative Affectivity Schedule (PANAS; Watson, Clark, \& Tellegen, 1988). With 10 positive and 10 negative mood adjectives, participants reported the extent to which they identify with each adjective on a scale from 1 (very slightly) to 5 (extremely). Past research indicates internal consistency reliabilities were 0.91 for positive affectivity and 0.87 for negative affectivity (Diefendorff et al., 2011). This sample resulted in an alpha estimate of .91 for positive affectivity and .95 for negative affectivity. 


\section{CHAPTER III: RESULTS}

\section{Overview of Analyses}

\section{Descriptive Information and Hypothesis Testing}

Table 1 provides the descriptive information for positive affectivity, negative affectivity, positive display rules, negative display rules, and co-rumination. This table also includes the intercorrelations between these variables and scale reliability estimates. The means, standard deviations, and scale reliability estimates aligned with past research across all scales, except for the positive display rules scale. Compared to past research, the positive display rules scale resulted in a weaker reliability estimate (Diefendorff et al., 2005). Although the coefficients were small, affectivity and display rules were significantly correlated in the expected directions. Display rules and co-rumination were not correlated in the expected directions. Specifically, negative display rules were not significantly related to co-rumination, and positive display rules were significantly positively related to co-rumination. Lastly, both negative and positive affectivity were significantly positively correlated with co-rumination. In addition, Table 2 provides the descriptive information for the co-rumination scale across participants from different occupational groups. 
Table 1

Correlations, Means and Standard Deviations for the Variables of Interest $(N=338)$

\begin{tabular}{lcccccc}
\hline Variable & $M(S D)$ & 1 & 2 & 3 & 4 & 5 \\
\hline 1. Positive Affectivity & $34.32(8.32)$ & $(.91)$ & & & & \\
2. Negative Affectivity & $20.45(10.02)$ & -.00 & $(.95)$ & & & \\
3. Positive Display Rules & $3.87(0.79)$ & $.15^{* *}$ & $-.21 * * *$ & $(.69)$ & & \\
4. Negative Display Rules & $3.50(1.06)$ & .02 & $.19 * * *$ & $.30 * * *$ & $(.86)$ & \\
5. Co-rumination & $3.27(0.86)$ & $.28 * * *$ & $.23 * * *$ & $.12 * *$ & .10 & $(.91)$ \\
\hline Observed Range & & & & & & \\
\hline
\end{tabular}

Table 2

Co-rumination Levels by Occupation Type

Occupation Type

Computer and Mathematical Occupations

Sales and Related Occupations

Educational Instruction and Library Occupations

Business and Financial Operations Occupations

Management Occupations

Healthcare Practitioners and Technical Occupations

Arts, Design, Entertainment, Sports, and Media Occupations n $\quad M(S D)$

$52 \quad 3.38(0.75)$

$42 \quad 3.19(0.93)$

$33 \quad 3.38(0.81)$

$33 \quad 3.23(0.97)$

$22 \quad 3.70(0.66)$

$21 \quad 3.22(1.07)$

$20 \quad 3.23(0.84)$

Note: While 22 different occupations were reflected in the sample, this table only lists the occupational groups with at least 20 participants. 


\section{Hypothesis Testing}

The correlation coefficients between affectivity, display rules, and co-rumination were used to test Hypotheses 1 through 3. The simple mediation Model 4 of Hayes' PROCESS macro on SPSS software was used to test Hypothesis 4 (Hayes, 2018). Lastly, the conditional process analysis Model 74 of Hayes' PROCESS macro was used to test Hypotheses 5 and 6 . To test our first hypothesized model with Model 74, trait negative affect was entered as the predictor, negative display rule perceptions were entered as the mediator, and co-rumination was entered as the dependent variable. This model also examined negative affectivity as a moderator of the relation between negative display rule perceptions and co-rumination. In the second hypothesized model, trait positive affect was entered as the predictor, positive display rule perceptions were entered as the mediator, and co-rumination was entered as the dependent variable. This model also examined positive affect as a moderator of the relation between positive display rule perceptions and co-rumination. In both models, the confidence intervals were produced using a bias-corrected method with 1,000 bootstrap samples (Hayes, 2018).

\section{Hypothesis 1}

First, the correlation coefficients were examined within each model to test the direct relations between affectivity and display rule perceptions. It was predicted that negative affectivity would lead to increased levels of negative display rule perceptions and that positive affectivity would lead to increased levels of positive display rule perceptions. As predicted, negative affectivity significantly predicted negative display rule perceptions, $\beta=.19, t(338)=$ $3.60, p<.001$, and positive affectivity significantly predicted positive display rule perceptions, $\beta=.15, t(338)=2.73, p=.007$. Thus, Hypothesis 1 was supported. 


\section{Hypothesis 2}

Next, a bivariate regression analysis was conducted within each model to examine the direct relations between display rule perceptions and co-rumination. It was predicted that negative display rules would be positively related to co-rumination while positive display rules would be negatively related to co-rumination. Negative display rule perceptions did not significantly predict co-rumination, $\beta=.10, t(338)=1.89, p=.060$, failing to support Hypothesis 2a. Positive display rule perceptions were found to positively predict co-rumination, $\beta=.12, t(338)=2.26, p=.025$. This suggests that work environments with positive, but not negative display rules, lead to co-rumination. Thus, Hypothesis 2 was not supported.

\section{Hypothesis 3}

To examine Hypotheses $3 \mathrm{a}$ and $3 \mathrm{~b}$, the direct effects between affectivity and corumination were examined using bivariate regression analyses within both models. It was predicted that negative affectivity would be positively related to co-rumination while positive affectivity would be negatively related to co-rumination. Negative affectivity was found to positively predict co-rumination, $\beta=0.23, t(338)=4.34, p<.001$, thus supporting Hypothesis 3a. Positive affectivity was also found to positively (not negatively) predict co-rumination, $\beta=$ $0.28, t(338)=5.30, p<.001$. This indicates that both positive and negative affectivity lead to corumination in the workplace. Thus, Hypothesis $3 \mathrm{a}$ was supported while Hypothesis $3 \mathrm{~b}$ was not supported.

\section{Hypothesis 4}

Next, the indirect effects between affectivity and co-rumination through display rule perceptions were examined. First, it was predicted that negative display rule perceptions would mediate the positive relation between negative affectivity and co-rumination (Hypothesis $4 \mathrm{a}$ ). 
Second, it was predicted that positive display rule perceptions would mediate the negative relation between negative display affectivity and co-rumination (Hypothesis $4 \mathrm{~b}$ ). The findings suggest that negative display rule perceptions did not mediate the relation between negative affectivity and co-rumination, $b=.00, \mathrm{CI}[-.0011, .0032]$. Positive display rule perceptions also did not mediate the relation between positive affectivity and co-rumination, $b=.00$, CI [-.0005, .0037]. This indicates that mediation was not present in either of the given models, suggesting that Hypothesis 4 was not supported.

\section{Hypothesis 5}

Next, the interaction terms between display-rule perceptions and affectivity were examined to test for moderation. The interaction term between negative affectivity and negative display rules was not statistically significant, $b=.00, t(338)=0.38, p=.706$, suggesting that negative affectivity did not moderate the negative display rules-co-rumination association. By examining the simple slopes, this conclusion was further supported (see Figure 4). The association between negative display rules and co-rumination at different levels of negative affectivity (i.e., mean, $1 \mathrm{SD}$ above, $1 \mathrm{SD}$ below) revealed non-significant slopes across all three levels. As shown in Figure 4, the display rules-co-rumination association was non-significant at low levels of negative affectivity $(b=.04, p=.51)$, moderate levels of negative affectivity ( $b=$ $.06, p=.25)$, and high levels of negative affectivity $(b=.08, p=.39)$. Thus, the three simple slopes were significantly different from zero, but not significantly different from each other. 


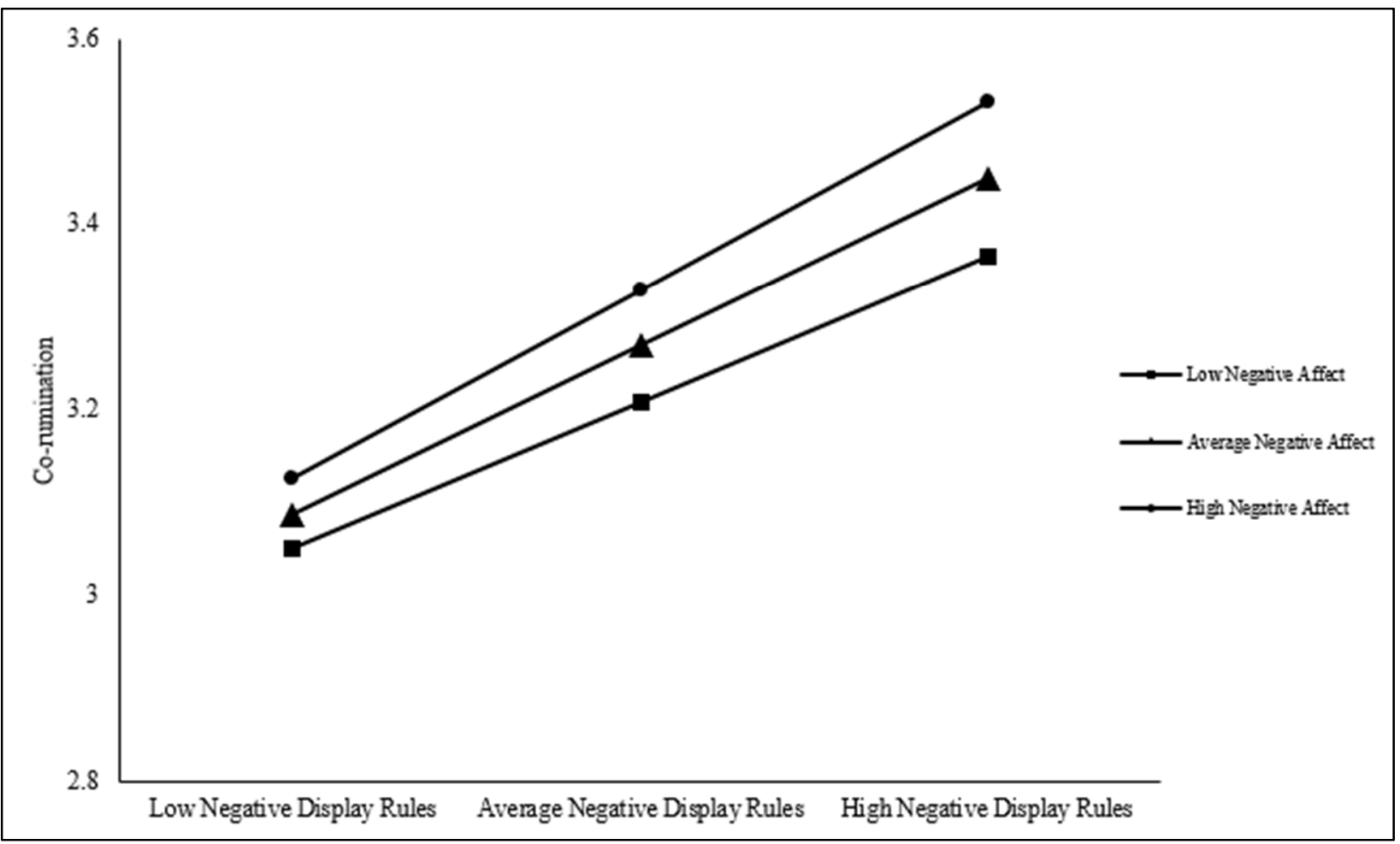

Figure 4. Plot of two-way interaction between negative display rules and negative affectivity.

The interaction term between positive affectivity and positive display rules was also not statistically significant, $b=.00, t(338)=0.14, p=.885$, similarly indicating that positive affectivity did not moderate the association between positive display rules-and co-rumination. By examining the simple slopes (see Figure 5), this conclusion was further supported. The association between positive display rules and co-rumination at different levels of positive affectivity (i.e., mean, 1 SD above, 1 SD below) revealed non-significant slopes across all three levels. As shown in Figure 5, the display rules-co-rumination association was non-significant at low levels of positive affectivity $(b=.08, p=.30)$, moderate levels of positive affectivity $(b=$ $.09, p=.12)$, and high levels of positive affectivity $(b=.10, p=.24)$. Thus, the three simple slopes were significantly different from zero, but not significantly different from each other. Given that moderation was not present in either model, Hypothesis 5 was not supported. 


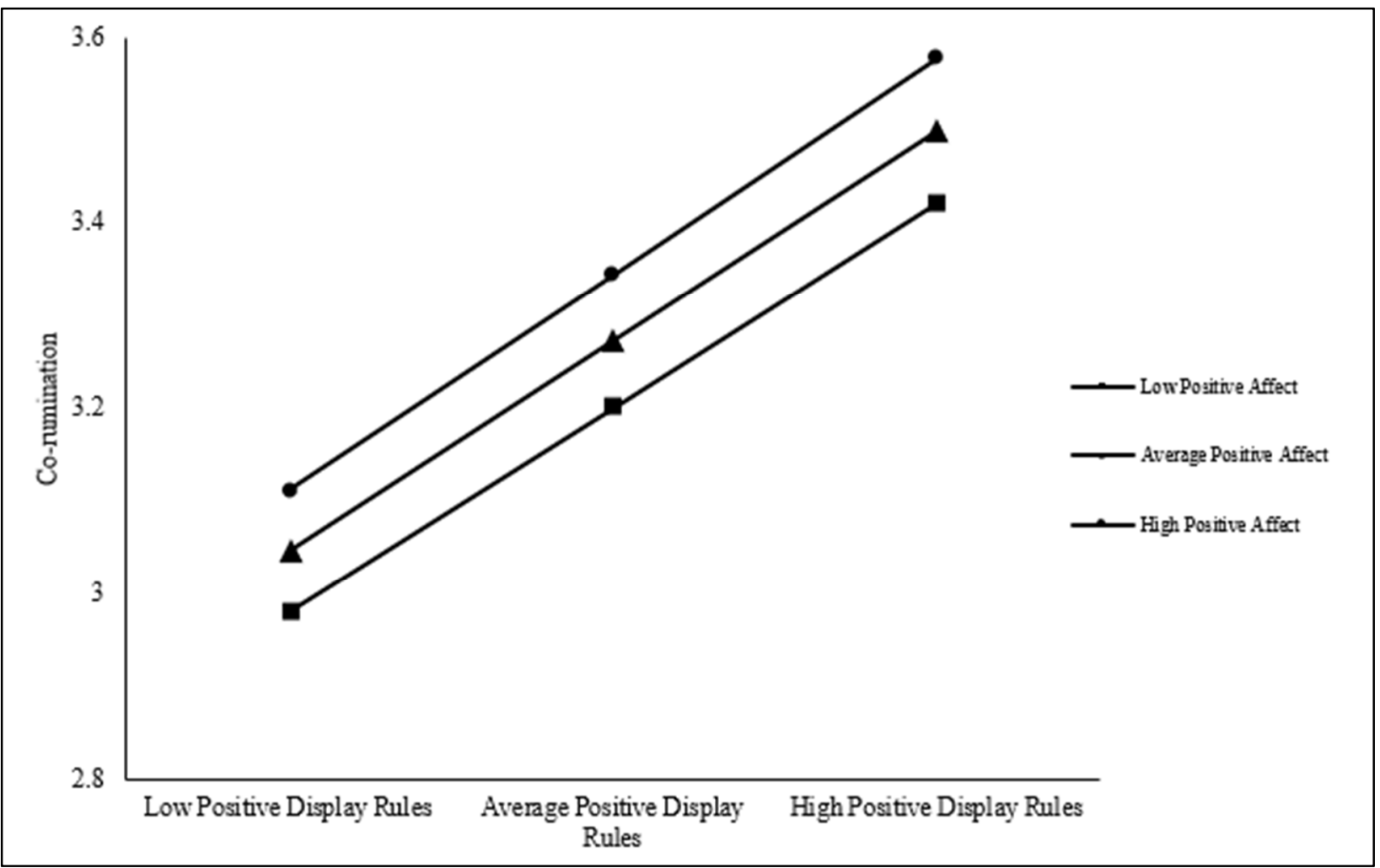

Figure 5. Plot of two-way interaction between positive display rules and positive affectivity.

\section{Hypothesis 6}

Lastly, the moderated-mediation hypotheses were examined in both models. Hypothesis 6 examined the extent to which mediation (Hypothesis 4) was contingent upon different levels of trait affect (Hypothesis 5). Specifically, it was predicted that the extent to which negative display rule perceptions mediate the relation between negative affect and co-rumination would depend upon levels of negative affect, such that mediation would be stronger under high negative affectivity than under low negative affectivity (Hypothesis 6a). Next, it was predicted that the extent to which positive display rules mediate the relation between positive affectivity and corumination would depend upon levels of positive affectivity, such that the mediation will be stronger under high positive affectivity than under low positive affectivity (Hypothesis 6b). The index of moderated mediation was used to test both models This index quantifies the effect of a 
moderator (i.e., affectivity) on the indirect effect of a predictor (i.e., affectivity) on an outcome variable (i.e., co-rumination) through a mediator (i.e., display rules). Further, this value represents the difference in slopes for the mediator at different levels of the moderator to examine whether there is a significant difference in the indirect effect when the moderator is added to the model (Hayes, 2018).

In the first model, the test of the index of moderated mediation of .00 indicated that the moderated indirect effect of negative affectivity on co-rumination was not statistically significant, CI [-.0002, .0003]. In the second model, the index of moderated mediation was again .00 ; the moderated indirect effect of positive affectivity on co-rumination was also not statistically significant, CI [-.0003, .0003]. Thus, Hypothesis 6 was not supported, confirming that moderated mediation was not present in either of the two models. Table 3 and Table 4 provide an overview of the findings across both models.

Table 3

Moderated-Mediation Analysis with Negative Affectivity and Negative Display Rules $(N=338)$

\section{Criterion}

\section{Negative Display Rules Co-rumination}

\begin{tabular}{lcccccc}
\cline { 2 - 6 } Predictor & Coeff. & $S E$ & $\mathrm{p}$-value & Coeff. & $S E$ & $\mathrm{p}$-value \\
\hline NA & .19 & .13 & $<.001$ & .23 & .01 & $<.001$ \\
NDR & - & - & - & .10 & .04 & .06 \\
NA x NDR & - & - & - & .00 & .02 & .71
\end{tabular}

Note: Index of moderated-mediation $=.00$. A bootstrap confidence interval based on 1,000 bootstrap samples included 0 in the interval, CI [-.0002, .0003], meaning the moderatedmediation model was non-significant. $R^{2}=.06, F(334,3)=7.71, p<.001$. 
Table 4

Moderated-Mediation Analysis with Positive Affectivity and Positive Display Rules $(N=338)$

\begin{tabular}{c} 
Criterion \\
\hline Positive Display Rules Co-rumination
\end{tabular}

\begin{tabular}{lcccccc}
\cline { 2 - 6 } Predictor & Coeff. & $S E$ & $\mathrm{p}$-value & Coeff. & $S E$ & p-value \\
\hline PA & .15 & .01 & .007 & .28 & .00 & $<.001$ \\
PDR & - & - & - & .12 & .06 & .03 \\
PA x PDR & - & - & - & .00 & .01 & .89 \\
& & & & & &
\end{tabular}

Note: Index of moderated-mediation $=.00$. A bootstrap confidence interval based on 1,000

bootstrap samples included 0 in the interval, CI [-.0003, .0003], meaning the moderated-

mediation model was non-significant. $R^{2}=.08, F(334,3)=10.18, p<.001$. 


\section{CHAPTER IV: DISCUSSION}

\section{Summary of Findings}

The primary objective of this study was to understand how affectivity and emotional display rules influence the way employees discuss workplace problems. More specifically, this study examined the impact of negative affectivity on co-rumination, and whether negative display rules mediated the expected negative effect of negative affectivity on co-rumination. The relation between positive affectivity and co-rumination was also explored, in addition to the mediating role of positive display rules on the proposed negative relation between positive affectivity and co-rumination. Within both models, affectivity was examined as a moderator of its own indirect effect, thus allowing for the examination of moderated-mediation.

In terms of the first model, negative affectivity was positively associated with negative display rules (Hypothesis 1a), thereby confirming that employees high in negative affect exhibit negative display rule perceptions. Hypothesis 2 a was not supported, suggesting that employees with negative display rule perceptions did not exhibit increased co-rumination in the given sample. Negative affectivity predicted increased levels of co-rumination, thus confirming Hypothesis 3a. However, negative display rule perceptions did not mediate the relation between affectivity and co-rumination (Hypothesis 4a). Hypothesis 5a stated that negative affectivity would moderate the positive relation between negative display rules and co-rumination, such that the positive relation would be stronger given high levels of negative affectivity. This was not supported by the results, suggesting that negative affectivity did not influence the extent to which negative display rule perceptions impacted employees' levels of co-rumination. Given the lack of evidence for moderation, it follows that moderated mediation would not be present. The results 
validated this conclusion by indicating that mediation was not dependent upon given levels of negative affectivity (Hypothesis 6a).

Within the second model, employees high in positive affectivity were found to exhibit positive display rule perceptions (Hypothesis $1 b$ ). Contrary to Hypothesis $2 b$, employees with positive display rule perceptions exhibited increased levels of co-rumination, not the expected decreased levels. Further, positive affectivity predicted increased levels of co-rumination, thus failing to support the notion that positive affectivity would be negatively associated with corumination (Hypothesis 3b). Positive display rule perceptions did not mediate the relation between affectivity and co-rumination (Hypothesis $4 b$ ), suggesting that positive display rules do not explain the positive relation between PA and co-rumination. Hypothesis $5 \mathrm{~b}$ stated that positive affectivity would moderate the negative relation between positive display rules and corumination, such that the positive relation would be stronger given high levels of positive affectivity. This was not supported by the results, suggesting that positive affectivity did not influence the extent to which positive display rule perceptions impacted employees' levels of corumination in the workplace. Again, given the lack of evidence for moderation, it follows that moderated mediation would not be present. As observed in Model 1, the results validated this conclusion by indicating that mediation was not dependent upon given levels of positive affectivity (Hypothesis 6b).

\section{General Discussion}

As expected, negative affectivity predicted negative display rule perceptions while positive affectivity predicted positive display rule perceptions. This indicates that affectivity may influence the way employees interpret the emotional demands of their work environment. Further, this study confirms previous findings on affectivity and display rules in organizations 
(Brotheridge \& Grandey, 2002; Kammeyer-Mueller et al., 2013; Rouxel et al., 2016). The traitcongruency processing framework can be used to explain the given relations. As suggested by Rusting (1998), affectivity is one individual trait that influences the extent to which individuals attend to given stimuli. This suggests that positive employees are more likely to attend to the positive features of their work environment, such as demands to smile or greet others at work. However, negative employees are more prone to noticing negative features, such as demands to hide negative feelings and facial expressions. By attending to such stimuli, positive and negative employees experience different outcomes in their perceptions of the emotional framework of their workplace.

In addition, employees high in negative or positive affectivity may receive feedback consistent with their emotional expressions. Referred to as the evocative gene-environment correlational process, research suggests that individual traits tend to evoke specific environmental responses (Jaffee \& Price, 2010). As individuals high in negative affect are prone to exhibiting negative affect expression (Carver \& Connor-Smith, 2010), they may evoke responses from other employees in accordance with their behavior. In this way, negative employees may be reprimanded in response to their negative expressions at work. This may similarly apply to employees high in positive affect, thus leading others to encourage their positive behavior in the workplace. In this way, evocative gene-environment correlational processes may further explain the relation between affectivity and display rules.

This study also examined the relation between display rule perceptions and corumination. Given the benefits of expressing positive emotions in the workplace (Diefendorff \& Richard, 2003; Kim, 2008), I predicted that positive display rules would decrease co-rumination levels. However, employees with positive display rule perceptions were found to exhibit 
increased levels of co-rumination in this sample. An expanded view of the emotional labor literature can be used to examine the complexities of the given display rule outcomes. In addition to the benefits of positive display rules, past research has identified some consequences, including increased emotional exhaustion (Becker, 2013) and psychosomatic complaints (Montgomery et al., 2006). Regardless of felt emotions, employees in such environments may be required to consistently act positively. Thus, workplaces with positive display rule requirements may be emotionally taxing over time, especially in the presence of rude or hostile interactions at work (Becker, 2013). Thus, the emotional labor involved in such environments may override the benefits of expressing positive emotions. This may explain why employees with positive display rule perceptions were compelled to express their frustrations with co-workers. Becker (2013) similarly identified contradictory findings with regard to positive display rule environments, indicating that positive display rules have been linked with both positive and negative outcomes. Becker explained that these conflicting findings on positive display rules have yet to be reconciled in the literature. Thus, more research is needed to identify the contexts in which positive display rules are helpful or harmful to employees.

Second, negative display rules were not found to increase co-rumination levels. This suggests that employees with negative display rule perceptions experience the workplace differently than expected. For example, employees may be encouraged to avoid complaining or extensively discussing workplace issues, thus leading them to avoid co-ruminating in the workplace. However, given the negative effects of environments with negative display rules (e.g., Brotheridge \& Grandey, 2002; Chau, 2007), employees may still feel compelled to coruminate. However, it may be that these employees are more likely to co-ruminate with individuals outside of the workplace. Future research is needed to empirically validate this 
assertion. As discussed previously, the approach-avoidance framework asserts that negative goals tend to lead to avoidant responses (McNaughton et al., 2016). By receiving negatively focused emotional goals (e.g., demands to hide emotions), employees may avoid dealing with any of the consequences. As a result, they may feel less compelled to seek social support through co-ruminative behaviors. This may explain why employees with negative display rule perceptions failed to exhibit increased co-rumination.

This was the first study to consider the linkage between affectivity and co-rumination. Both negative and positive affectivity predicted increased co-rumination. Thus, co-rumination may occur regardless of one's affectivity. In terms of negative affectivity, these findings confirmed my prediction. Given the positive relation between negative affectivity and rumination (Costa et al., 2018), neuroticism (Joseph et al., 2015), and negative affect expression (Carver \& Connor-Smith, 2010), it is reasonable to expect negative individuals to also engage in excessive problem talk. Again drawing on trait congruency theory, negative employees may be more prone to noticing negative features of their work environment, thus leading them to co-ruminate.

However, the findings for positive affectivity contradicted my prediction. Past research suggests positive affectivity is related to positive rumination (Hamilton et al., 2017), characterized by amplifying one's positive affective experiences. While employees high in positive affect likely still discuss their problems at work, their discussions may focus more strongly on the positive aspects of their issues. Recent research supports this notion by indicating that some components of co-rumination (i.e., mutual encouragement of problem talk) are related to positive outcomes (i.e., positive friendship adjustment) while other components (i.e., dwelling on negative affect) are related to negative outcomes (Rose et al., 2014). Given that only one item on the positive display rules scale explicitly refers to negative emotions, individuals high in 
positive affect may have interpreted the co-rumination scale items differently from individuals high in negative affect. Further, past research suggests that positive affectivity and extraversion are strongly positively correlated (Işı1k \& Üzbe, 2015). Thus, positive employees may be more likely to engage in conversations with co-workers, thus increasing their likelihood of coruminating.

Both negative and positive display rules were not found to mediate the affect-corumination relations. These findings can be further examined by recent advancements in the display rules and emotional labor literature. Specifically, emotional labor has been characterized by two primary components: (1) emotional demands and (2) the strategies employed to meet the given demands (Grandey \& Sayre, 2019). The first component refers to display rules while the second refers to the employees' behaviors in response to the given emotional framework. Specifically, the second component refers to the emotional regulation strategies employed to align with display rules, including altering emotions to appear genuine (i.e., deep acting) and faking the expected emotion (i.e., surface acting) (Grandey \& Sayre, 2019). Given that this study did not account for emotion regulation strategies, including deep and surface acting, the proposed mediating relations could have been impacted. In this way, display rule perceptions alone may not explain the relation between affectivity and co-rumination. Rather, the emotional regulation strategies employed in response to such display rules may also permit consideration within the given models.

As both positive and negative affectivity were not found to moderate the display rule-corumination relations, this indicates a need to identify other moderators. As discussed previously, surface acting and deep acting may serve an important role in assessing display rule outcomes. Past research suggests that surface acting leads to negative outcomes, including emotional 
exhaustion (Halbesleben, Wheeler, \& Paustian-Underdahl, 2013) and job stress (Jung \& Yoon, 2014). Comparably, due to the authentic nature of deep acting, this emotion regulation strategy has been associated with more favorable outcomes, including increased customer satisfaction (Chi \& Chen, 2019). Given different emotional regulation responses to various display rule environments, employees would be likely to exhibit different outcomes. Although this provides one possible direction for future research, more research is needed to fully validate the notion that affectivity does not impact the display rule-co-rumination relations.

\section{Limitations}

Given the cross-sectional nature of the data collected in this study, the regression analyses must be interpreted with caution. One requirement to establish causality is that the temporal precedence of variables must be determined (Oppewal, 2010). Longitudinal research is needed to determine whether the temporal ordering of the affectivity, display rules, and corumination variables is accurate. Specifically, past research on co-rumination suggests that longitudinal studies are needed to differentiate this construct from similar behaviors, such as short-term venting sessions (Boren, 2014).

Another limitation is that this study was conducted using only self-report measures. This indicates that the findings may be susceptible to common-method variance (Campbell \& Fisk, 1959). Future research should employ more diverse forms of measurement to reduce the impact

of common-method bias. Consistent with recent approaches in display rule methodology, display rules could be measured at the unit-level of analysis to examine shared perceptions within work groups (Diefendorff et al., 2011). In addition to self-reported affectivity measures, other employees (e.g., peers, direct reports, supervisors) could be sampled to examine convergence 
across sources. As employed in a recent study, co-rumination could be examined observationally (Rose et al., 2014) within dyadic work relationships over time.

From a measurement perspective, the limitations of MTurk as a data collection platform must be discussed. As mentioned previously, recent research has identified methodological concerns in utilizing MTurk for data collection (Cheung et al., 2017). While concerns related to subject inattentiveness and sample representativeness were addressed in this study, other measures could have been taken as well. To further address subject inattentiveness, past research recommends including a prompt that instructs participants to respond accurately (Huang et al., 2015). Specifically, the researchers recommend stating that response patterns will be monitored and that random responses will not be compensated. In their study, this prompt led to a decrease in insufficient effort responding. Second, one of the main extraneous factors in MTurk samples includes the different environmental settings across participants. To control for environmental settings, Huang et al (2015) recommend instructing participants to complete the survey under specific conditions (e.g., quiet room, specific browser). Lastly, the issue of sample representativeness and appropriateness must be examined. While qualification measures were taken to obtain an appropriate/representative sample, it is also recommended that content related to the qualifications are embedded into the questionnaire. For example, if participants are required to be full time employees, Huang and researchers (2015) suggest including an item that could only be answered by a full-time employee (e.g., position, schedule, salary). To reduce the risk of methodological concerns with MTurk, future research could employ these strategies.

While this study examined display rule perceptions, display rule emotional regulation strategies were not considered. Recent approaches in emotional labor theory have identified two components of the emotional labor process. These two components include emotional demands 
and the strategies employed to meet the given demands (i.e., surface/deep acting) (Grandey \& Sayre, 2019). Thus, my findings are limited by failing to consider the ways in which employees behaviorally respond to the given display rule environment. As suggested previously, future studies should include surface and deep acting scales to examine how display rules strategies impact the display rules-co-rumination association.

Past research has reported a reliability coefficient of .73 on scores from the positive display rules scale used in this study (Diefendorff et al., 2005). The positive display rule scores in this sample revealed a reliability coefficient of .69 , failing to reach satisfactory reliability levels. This may be attributable to my adaptation of the display rule scale for this sample. Specifically, all items containing the word "customers" were changed to include "customers, clients, co-workers". The positive display rule scale also included a reverse-scored item, suggesting that MTurk participants may have failed to read the items closely.

\section{Theoretical and Practical Implications}

While some limitations were present, implications for both practice and theory can be drawn from this study. Recent research indicates that the process by which co-rumination occurs in the workplace is not yet understood (Boren, 2014; Haggard et al., 2010). This is the first study to consider this process, by examining both individual-level and organizational-level antecedents. The present study adds to the current literature by demonstrating that positive affectivity, negative affectivity, and positive display rule perceptions are predictive of corumination at work. While future research is needed to determine whether these findings can be replicated in organizational samples outside of MTurk, the findings support theoretical assertions that individual and organizational characteristics impact behavior. 
In an organizational context, this study has important implications for the well-being of employees. Given that co-rumination leads to work-to-family conflict (Haggard et al., 2011), employee stress (Boren, 2014), and emotional exhaustion (Boren, 2013), it is important for managers to monitor negative problem talk that occurs among their employees. First, this study suggests that managers should pay attention to their employees' individual traits that may make them susceptible to joining negative conversations with co-workers. Second, managers should be mindful of the emotional environment they create in order to offer opportunities for employees to discuss workplace issues in a manner that is socially supportive, rather than destructive. Third, managers could discuss the consequences of co-rumination with their employees and help employees to identify the process by which it occurs in their day-to-day experiences at work. Although more research is needed to validate these managerial implications, this study has started a foundation by contributing to the co-rumination literature.

As only five studies have examined co-rumination in the workplace (e.g., Boren, 2013, 2014; Haggard et al., 2010), this study identifies a need for continued research on co-rumination in organizations. While past research has identified the consequences of co-rumination for employees, more research is needed to determine the antecedents of this construct. By continuing this research organizations will not only be able to understand the impact of co-rumination, but also learn how to support the emotional needs of their employees. 


\section{REFERENCES}

Abramowitz, J. S., Tolin, D. F., \& Street, G. P. (2001). Paradoxical effects of thought suppression: a meta-analysis of controlled studies. Clinical Psychology Review, 21, 683703. doi: 10.1016/s0272-7358(00)00057-x

Allen, J. A., Pugh, S. D., Grandey, A. A., \& Groth, M. (2010). Following display rules in good or bad faith?: Customer orientation as a moderator of the display rule-emotional labor relationship. Human Performance, 23, 101-115. doi: 10.1080/08959281003621695

American Psychological Association. (2009). Stress in America 2009. Retrieved from http://www.apa.org/news/press/releases/stress-exec-summary.pdf

Ashforth, B. E., \& Humphrey, R. H. (1993). Emotional labor in service roles: The influence of identity. The Academy of Management Review, 18, 88-115. doi: 10.2307/258824

Ashkanasy, N. M., Zerbe, W. J., \& Hartel, C. E. (2016). Managing emotions in the workplace. Armonk, NY: M.E. Sharpe.

Baron, R. M., \& Kenny, D. A. (1986). The moderator-mediator variable distinction in social psychological research: Conceptual, strategic, and statistical considerations. Journal of Personality and Social Psychology, 51, 1173-1182. doi: 10.1037/0022-3514.51.6.1173

Barsade, S. G., \& Gibson, D. E. (2007). Why does affect matter in organizations?. Academy of Management Perspectives, 21, 36-59. doi: 10.5465/amp.2007.24286163

Becker, C. J. (2013). Examining the Effects of Display Rule Content and Individual Differences on Well-being, Performance, and Self-Regulatory Resource Depletion. (Doctoral dissertation, University of Akron). 
Behrend, T. S., Sharek, D. J., Meade, A. W., \& Wiebe, E. N. (2011). The viability of crowdsourcing for survey research. Behavior Research Methods, 43, 800-813. doi: $10.3758 / \mathrm{s} 13428-011-0081-0$

Ben-Naim, S., Hirschberger, G., Ein-Dor, T., \& Mikulincer, M. (2013). An experimental study of emotion regulation during relationship conflict interactions: The moderating role of attachment orientations. Emotion, 13, 506-519. doi: 10.1037/a0031473

Boren, J. P. (2013). Co-rumination partially mediates the relationship between social support and emotional exhaustion among graduate students. Communication Quarterly, 61, 253267. doi: 10.1080/01463373.2012.751436

Boren, J. P. (2014). The relationships between co-rumination, social support, stress, and burnout among working adults. Management Communication Quarterly, 28, 3-25. doi: $10.1177 / 0893318913509283$

Brenning, K., Soenens, B., Van Petegem, S., \& Vansteenkiste, M. (2015). Perceived maternal autonomy support and early adolescent emotion regulation: A longitudinal study. Social Development, 24, 561-578. doi: 10.1111/sode.12107

Brotheridge, C. M., \& Grandey, A. A. (2002). Emotional labor and burnout: Comparing two perspectives of "people work". Journal of Vocational Behavior, 60, 17-39. doi: 10.1006/jvbe. 2001.1815

Butler, E. A., Egloff, B., Wlhelm, F. H., Smith, N. C., Erickson, E. A., \& Gross, J. J. (2003). The social consequences of expressive suppression. Emotion, 3, 48-67. doi: 10.1037/15283542.3 .1 .48

Campbell, D. T., \& Fisk, D. W. (1959). Convergent and discriminant validation by multitraitmultimethod matrix. Psychological Bulletin, 56, 81-105. 
Carver, C. S., \& Connor-Smith, J. (2010). Personality and coping. Annual Review of Psychology, 61, 679-704. doi: 10.1146/annurev.psych.093008.100352

Chau, S.L. (2007). Examining the emotional labor process: A moderated model of emotional labor and its effects on job performance and turnover. (Unpublished doctoral dissertation). University of Akron.

Cheung, J. H., Burns, D. K., Sinclair, R. R., \& Sliter, M. (2017). Amazon Mechanical Turk in organizational psychology: An evaluation and practical recommendations. Journal of Business and Psychology, 32, 347-361. doi: 10.1007/s10869-016-9458-5

Chou, P. (2015). The effects of workplace social support on employee's subjective well-being. European Journal of Business and Management, 7, 8-19.

Cohen, M. (2013). The association of cancer patients' emotional suppression and their self-rating of psychological distress on short screening tools. Behavioral Medicine, 39, 29-35. doi: $10.1080 / 08964289.2012 .731440$

Cohen, S., Underwood, L., \& Gottlieb, B. H. (2000). Social support measurement and intervention: a guide for health and social scientists. New York: Oxford University Press.

Connolly, J. J., \& Viswesvaran, C. (2000). The role of affectivity in job satisfaction: A metaanalysis. Personality and Individual Differences, 29, 265-281. doi: 10.1016/S01918869(99)00192-0

Costa, J., Gouveia, J. P., \& Marôco, J. (2018). The role of negative affect, rumination, cognitive fusion and mindfulness on depressive symptoms in depressed outpatients and normative individuals. International Journal of Psychology \& Psychological Therapy, 18, 207-220. 
Dalgleish, T., Yiend, J., Schweizer, S., \& Dunn, B. D. (2009). Ironic effects of emotion suppression when recounting distressing memories. Emotion, 9, 744-749. doi: $10.1037 / \mathrm{a} 0017290$

Diefendorff, J. M., \& Gosserand, R. H. (2003). Understanding the emotional labor process: A control theory perspective. Journal of Organizational Behavior, 24, 945-959. doi: 10.1002/job. 230

Diefendorff, J. M., \& Richard, E. M. (2003). Antecedents and consequences of emotional display rule perceptions. Journal of Applied Psychology, 88, 284-294. doi: 10.1037/00219010.88 .2 .284

Diefendorff, J. M., Croyle, M. H., \& Gosserand, R. H. (2005). The dimensionality and antecedents of emotional labor strategies. Journal of Vocational Behavior, 66, 339357. doi: 10.1016/j.jvb.2004.02.001

Diefendorff, J. M., Erickson, R. J., Grandey, A. A., \& Dahling, J. J. (2011). Emotional display rules as work unit norms: a multilevel analysis of emotional labor among nurses. Journal of Occupational health Psychology, 16, 170-186. doi: 10.1037/a0021725

Diefendorff, J. M., Richard, E. M., \& Croyle, M. H. (2006). Are emotional display rules formal job requirements? Examination of employee and supervisor perceptions. Journal of Occupational and Organizational Psychology, 79, 273-298. doi:

\section{$10.1348 / 096317905 \times 68484$}

D'Lima, G. M., Pearson, M. R., \& Kelley, M. L. (2012). Protective behavioral strategies as a mediator and moderator of the relationship between self-regulation and alcohol-related consequences in first-year college students. Psychology of Addictive Behaviors, 26, 330. doi: $10.1037 / \mathrm{a} 0026942$ 
Ekman, P., \& Friesen, W. V. (1969). The repertoire of nonverbal behavior: Categories, origins, usage, and coding. Semiotica, 1, 49-98. doi: 10.1515/semi.1969.1.1.49

Elliot, A. J., Sheldon, K. M., \& Church, M. A. (1997). Avoidance personal goals and subjective well-being. Personality and Social Psychology Bulletin, 23, 915-927. doi:

$10.1177 / 0146167297239001$

Feldman, G. C., Joormann, J., \& Johnson, S. L. (2008). Responses to positive affect: A selfreport measure of rumination and dampening. Cognitive Therapy and Research, 32, 507525. doi: 10.1007/s10608-006-9083-0

Felton, J. W., Cole, D. A., Havewala, M., Kurdziel, G., \& Brown, V. (2019). Talking together, thinking alone: relations among co-rumination, peer relationships, and rumination. Journal of Youth and Adolescence, 48, 731-743. doi: 10.1007/s10964-018-0937-z

Ferris, D. L., Yan, M., Lim, V. K., Chen, Y., \& Fatimah, S. (2016). An approach-avoidance framework of workplace aggression. Academy of Management Journal, 59, 1777-1800. doi: $10.5465 / \mathrm{amj} .2014 .0221$

Fredrickson, B. L., \& Branigan, C. (2005). Positive emotions broaden the scope of attention and thought $\square$ action repertoires. Cognition and Emotion, 19, 313-332. doi: $10.1080 / 02699930441000238$

Gerhart, J. I., Baker, C. N., Hoerger, M., \& Ronan, G. F. (2014). Experiential avoidance and interpersonal problems: A moderated mediation model. Journal of Contextual Behavioral Science, 3, 291-298. doi: 10.1016/j.jcbs.2014.08.003 
Goldberg, L. S., \& Grandey, A. A. (2007). Display rules versus display autonomy: emotion regulation, emotional exhaustion, and task performance in a call center simulation. Journal of Occupational Health Psychology, 12, 301-318. doi: 10.1037/10768998.12.3.301

Grandey, A. A., \& Sayre, G. M. (2019). Emotional labor: Regulating emotions for a wage. Current Directions in Psychological Science, 28, 131-137. doi:

$10.1177 / 0963721418812771$

Gross, J. J., \& Levenson, R. W. (1993). Emotional suppression: physiology, self-report, and expressive behavior. Journal of Personality and Social Psychology, 64, 970-986. doi: $10.1177 / 09637214188127$

Guarneri-White, M. E. (2017). Making a bad situation worse: Co-rumination and peer victimization in two adolescent samples. (Doctoral dissertation).

Haggard, D. L., Robert, C., \& Rose, A. J. (2011). Co-rumination in the workplace: Adjustment trade-offs for men and women who engage in excessive discussions of workplace problems. Journal of Business and Psychology, 26, 27-40. doi: 10.1007/s10869-010$9169-2$

Hamilton, J. L., Burke, T. A., Stange, J. P., Kleiman, E. M., Rubenstein, L. M., Scopelliti, K. A., \& Alloy, L. B. (2017). Trait affect, emotion regulation, and the generation of negative and positive interpersonal events. Behavior Therapy, 48, 435-447. doi: 10.1016/j.beth.2017.01.006

Harding, K. A., \& Mezulis, A. (2017). Is rumination a risk and a protective factor?. Europe's Journal of Psychology, 13, 28-46. doi: 10.5964/ejop.v13i1.1279 
Hayes, A. F. (2018). Fundamentals of conditional process analysis. In Introduction to mediation, moderation, and conditional process analysis: A regression-based approach (pp. 393430). New York: Guilford.

Hochschild, A. R. (1983). The managed heart: Commercialization of human feeling. Berkeley: University of California Press.

Hopp, H., Rohrmann, S., \& Hodapp, V. (2012). Suppression of negative and expression of positive emotions: Divergent effects of emotional display rules in a hostile service interaction. European Journal of Work and Organizational Psychology, 21, 84-105. doi: $10.1080 / 1359432 X .2010 .539327$

Hruska, L. C., Zelic, K. J., Dickson, K. S., \& Ciesla, J. A. (2017). Adolescents' co $\square$ rumination and stress predict affective changes in a daily $\square$ diary paradigm. International Journal of Psychology, 52, 372-380. doi: 10.1002/ijop.12227

Huang, J. L., Bowling, N. A., Liu, M., \& Li, Y. (2015). Detecting insufficient effort responding with an infrequency scale: Evaluating validity and participant reactions. Journal of Business and Psychology, 30, 299-311. doi: 10.1007/s10869-014-9357-6

Halbesleben, J. R., Wheeler, A. R., \& Paustian-Underdahl, S. C. (2013). The impact of furloughs on emotional exhaustion, self-rated performance, and recovery experiences. Journal of Applied Psychology, 98, 492.

Isik, S., \& Üzbe, N. (2015). Personality traits and positive/negative affects: An analysis of meaning in life among adults. Educational Sciences: Theory and Practice, 15, 587-595. doi: 10.12738/estp.2015.3.2436 
Joseph, D. L., Dhanani, L. Y., Shen, W., McHugh, B. C., \& McCord, M. A. (2015). Is a happy leader a good leader? A meta-analytic investigation of leader trait affect and leadership. The Leadership Quarterly, 26, 557-576. doi: 10.1016/j.leaqua.2015.04.001

Jung, H. S., \& Yoon, H. H. (2014). Antecedents and consequences of employees' job stress in a foodservice industry: Focused on emotional labor and turnover intent. International Journal of Hospitality Management, 38, 84-88.

Kahn, J. H., Schneider, K. T., Jenkins $\square$ Henkelman, T. M., \& Moyle, L. L. (2006). Emotional social support and job burnout among high $\square$ school teachers: is it all due to dispositional affectivity?. Journal of Organizational Behavior, 27, 793-807. doi: 10.1002/job.397

Kamijo, N., \& Yukawa, S. (2018). The role of rumination and negative affect in meaning making following stressful experiences in a Japanese sample. Frontiers in Psychology, 9, 1-9. doi: 10.3389/fpsyg.2018.02404

Kammeyer $\square$ Mueller, J. D., Rubenstein, A. L., Long, D. M., Odio, M. A., Buckman, B. R., Zhang, Y., \& Halvorsen $\square$ Ganepola, M. D. (2013). A meta $\square$ analytic structural model of dispositonal affectivity and emotional labor. Personnel Psychology, 66, 47-90. doi: 10.1111/peps. 12009

Kennedy-Moore, E., \& Watson, J. C. (2001). How and when does emotional expression help?. Review of General Psychology, 5, 187-212. doi: 10.1037/1089-2680.5.3.187

Kim, H.J. (2008). Hotel service providers' emotional labor: The antecedents and effects of burnout. International Journal of Hospitality Management, 27, 151-161. doi: 10.1016/j.ijhm.2007.07.019 
Leidner, R. (1999). Emotional labor in service work. In R. J. Steinberg \& D. M. Figart (Eds.), The Annals of the American Academy of Political and Social Science (pp. 81-95). Thousand Oaks, CA: Sage.

Lyubomirsky, S., King, L., \& Diener, E. (2005). The benefits of frequent positive affect: Does happiness lead to success?. Psychological Bulletin, 131, 803. doi: 10.1037/00332909.131.6.803

MacNeil, G., Kosberg, J. I., Durkin, D. W., Dooley, W. K., DeCoster, J., \& Williamson, G. M. (2010). Caregiver Mental Health and Potentially Harmful Caregiving Behavior: The Central Role of Caregiver Anger. Gerontologist, 50(1), 76-86. doi:

10.1093/geront/gnp099

Matthews, R. A., Bulger, C. A., \& Barnes-Farrell, J. L. (2010). Work social supports, role stressors, and work-family conflict: The moderating effect of age. Journal of Vocational Behavior, 76, 78-90. doi: 10.1016/j.jvb.2009.06.011

McNaughton, N., DeYoung, C. G., \& Corr, P. J. (2016). Approach/avoidance. In Neuroimaging personality, social cognition, and character (pp. 25-49). Academic Press.

Montgomery, A.J., Panagopolou, E., De Wildt, M., \& Meenks, E. (2006). Work-family interference, emotional labor and burnout. Journal of Managerial Psychology, 21, 3651. doi: $10.1108 / 02683940610643206$

Narayanan, L., Menon, S., \& Spector, P. E. (1999). Stress in the workplace: a comparison of gender and occupations. Journal of Organizational Behavior, 20, 63-73. doi: 10.1002/(sici)1099-1379(199901)20:1<63::aid-job873>3.3.co;2-a 
Nelis, S., Bastin, M., Raes, F., \& Bijttebier, P. (2018). When do good things lift you up?

Dampening, enhancing, and uplifts in relation to depressive and anhedonic symptoms in early adolescence. Journal of Youth and Adolescence, 47, 1712-1730. doi:

$10.1007 / \mathrm{s} 10964-018-0880-\mathrm{z}$

Oppewal, H. (2010). Concept of causality and conditions for causality. Wiley International

Encyclopedia of Marketing. doi: 10.1002/9781444316568.wiem02059

Pugh, S. D. (2001). Service with a smile: Emotional contagion in the service encounter. Academy of Management Journal, 44, 1018-1027. doi: 10.5465/3069445

Rafaeli, A., \& Sutton, R. I. (1987). Expression of emotion as part of the work role. Academy of Management Review, 12, 23-37. doi: 10.5465/amr.1987.4306444

Richards, J. M., \& Gross, J. J. (1999). Composure at any cost? The cognitive consequences of emotion suppression. Personality and Social Psychology Bulletin, 25, 1033-1044. doi: $10.1177 / 01461672992511010$

Rose, A. J. (2002). Co-rumination in the friendships of girls and boys. Child Development, 73, 1830-1843. doi: 10.1111/1467-8624.00509

Rose, A. J., Carlson, W., \& Waller, E. M. (2007). Prospective associations of co-rumination with friendship and emotional adjustment: Considering the socioemotional trade-offs of corumination. Developmental Psychology, 43, 1019-1031. doi: 10.1037/00121649.43.4.1019

Rose, A. J., Schwartz-Mette, R. A., Glick, G. C., Smith, R. L., \& Luebbe, A. M. (2014). An observational study of co-rumination in adolescent friendships. Developmental Psychology, 50, 2199-2209. doi: 10.1037/a0037465 
Rouxel, G., Michinov, E., \& Dodeler, V. (2016). The influence of work characteristics, emotional display rules and affectivity on burnout and job satisfaction: A survey among geriatric care workers. International Journal of Nursing Studies, 62, 81-89. doi: 10.1016/j.ijnurstu.2016.07.010

Roxana, A. C. (2013). Social support as a mediator between emotion work and job satisfaction. Procedia-Social and Behavioral Sciences, 84, 601-606. doi: 10.1016/j.sbspro.2013.06.611

Rusting, C. L. (1998). Personality, mood, and cognitive processing of emotional information: three conceptual frameworks. Psychological Bulletin, 124, 165-196. doi: 10.1037/00332909.124.2.165

Schaubroeck, J., \& Jones, J. R. (2000). Antecedents of workplace emotional labor dimensions and moderators of their effects on physical symptoms. Journal of Organizational Behavior, 21, 163-183. doi: 10.1002/(SICI)1099-1379(200003)21:2<163::AIDJOB37>3.0.CO;2-L

Schwartz-Mette, R. A., \& Smith, R. L. (2018). When does co-rumination facilitate depression contagion in adolescent friendships? Investigating intrapersonal and interpersonal factors. Journal of Clinical Child \& Adolescent Psychology, 47, 912-924. doi:

$10.1080 / 15374416.2016 .1197837$

Sias, P.M. (2009). Organizing relationships: traditional and emerging perspectives on workplace relationships. London: Sage.

Sims $\square$ Gould, J., \& Martin $\square$ Matthews, A. (2010). We share the care: Family caregivers’ experiences of their older relative receiving home support services. Health and Social Care in the Community, 18, 415-423. doi: 10.1111/j.1365-2524.2010.00913.x 
Starr, L. R. (2015). When support seeking backfires: Co-rumination, excessive reassurance seeking, and depressed mood in the daily lives of young adults. Journal of Social and Clinical Psychology, 34, 436-457. doi: 10.1521/jscp.2015.34.5.436

Sutton, R. I., \& Rafaeli, A. (1988). Untangling the relationship between displayed emotions and organizational sales: The case of convenience stores. Academy of Management journal, 31, 461-487. doi: 10.5465/256456

Swearingen, C., Byrd-Craven, J., \& Kennison, S. M. (2016). The relationship between corumination and health in young women: Evidence from Facebook communications. Psi Chi Journal of Psychological Research, 21, 111-1118. doi: 10.24839/21648204.JN21.2.111

Sy, T., Côté, S., \& Saavedra, R. (2005). The contagious leader: impact of the leader's mood on the mood of group members, group affective tone, and group processes. Journal of Applied Psychology, 90, 295-305. doi: 10.1037/0021-9010.90.2.295

Trougakos, J. P., Jackson, C. L., \& Beal, D. J. (2011). Service without a smile: Comparing the consequences of neutral and positive display rules. Journal of Applied Psychology, 96, 350-362. doi: $10.1037 / \mathrm{a} 0021880$

Valena, S. P., \& Szentagotái-Tatar, A. (2015). The relationships between stress, negative affect, rumination and social anxiety. Journal of Evidence-Based Psychotherapies, 15, 179-189.

Watson, D., \& Slack, A. K. (1993). General factors of affective temperament and their relation to job satisfaction over time. Organizational Behavior and Human Decision Processes, 54, 181-202. doi: 10.1006/obhd.1993.1009 
Watson, D., \& Walker, L. M. (1996). The long-term stability and predictive validity of trait measures of affect. Journal of Personality and Social Psychology, 70, 567-577. doi: $10.1037 / / 0022-3514.70 .3 .567$

Watson, D., Clark, L. A., \& Tellegen, A. (1988). Development and validation of brief measures of positive and negative affect: The PANAS scales. Journal of Personality and Social Psychology, 54, 1063-1070. doi: 10.1037/0022-3514.54.6.1063

Wegner, D. M. (1989). White bears and other unwanted thoughts: Suppression, obsession, and the psychology of mental control. Penguin Press.

Wegner, D. M. (1994). Ironic processes of mental control. Psychological Review, 101, 34-52. doi: $10.1037 / 0033-295 x .101 .1 .34$

Wong, E., Tschan, F., Messerli, L., \& Semmer, N. K. (2013). Expressing and amplifying positive emotions facilitate goal attainment in workplace interactions. Frontiers in Psychology, 4, 1-15. doi: 10.3389/fpsyg.2013.00188

Yam, K. C. (2018). The effects of thought suppression on ethical decision making: Mental rebound versus ego depletion. Journal of Business Ethics, 147, 65-79. doi: $10.1007 / \mathrm{s} 10551-015-2944-2$

Zelic, K. J., Ciesla, J. A., Dickson, K. S., Hruska, L. C., \& Ciesla, S. N. (2017). An experimental investigation of co-rumination, problem solving, and distraction. Behavior Therapy, 48, 403-412. doi: 10.1016/j.beth.2016.11.013

Zellars, K. L., \& Perrewé, P. L. (2001). Affective personality and the content of emotional social support: Coping in organizations. Journal of Applied Psychology, 86, 459-467. doi: $10.1037 / 0021-9010.86 .3 .459$ 